\title{
The association between psychiatric disorders and telomere length: A Meta-analysis involving 14,827 persons
}

\author{
Sabrina M Darrow, $\mathrm{PhD}^{1}$, Josine E Verhoeven, $\mathrm{MSc}^{2}$, Dóra Révész, MSc${ }^{2}$, Daniel Lindqvist, \\ MD, PhD ${ }^{1,3}$, Brenda WJH Penninx, PhD ${ }^{2}$, Kevin L Delucchi, PhD ${ }^{1}$, Owen M Wolkowitz, MD ${ }^{1}$, \\ and Carol A Mathews, MD ${ }^{1}$
}

${ }^{1}$ Department of Psychiatry, University of California, San Francisco ${ }^{2}$ Department of Psychiatry and EMGO Institute for Health and Care Research, VU University Medical Center, Amsterdam, The Netherlands ${ }^{3}$ Department of Clinical Sciences, Section for Psychiatry, Lund University

\begin{abstract}
Objective-This study examined the relationship between leukocyte telomere length (LTL), a marker of cell aging, and psychiatric disorders in adults compared to controls using meta-analytic methods.
\end{abstract}

Methods-Data were abstracted from studies examining the relationship between LTL and adult psychiatric disorders. In addition to an overall estimate of effect size, subgroup analyses and metaregression were performed to examine whether covariates (including psychiatric diagnoses) moderated the estimate.

Results-A significant overall effect size showing LTL shortening was found across all psychiatric disorders (Hedge's $g=-0.50, \mathrm{p}<0.001$ ). Subgroup analyses did not demonstrate significant differences in effect size based on individual covariates (psychiatric disorder, sex, age or assay method). The meta-regression indicated that although type of disorder and, likely, age moderate the overall effect size, the heterogeneity between studies could be explained by a model that included these variables as well as sex and assay method. Although not significantly different, post-traumatic stress disorder, anxiety disorders and depressive disorders had comparatively larger effect sizes $(-1.27,-.53$, and -.55$)$, and psychotic and bipolar disorders had comparatively smaller ones $(-.23$ and -.26$)$.

Conclusions-We observed a robust effect size of LTL shortening for psychiatric disorders as a whole compared to controls. The results were less straightforward regarding relative differences in the strength of this association by specific disorder. Future studies should focus on mechanisms explaining accelerated cell aging with psychiatric illness, defining directions (if any) of causality and elucidating possible differences in this association between disorders.

Address correspondence to Carol A. Mathews, M.D., Department of Psychiatry, University of California, San Francisco, 401 Parnassus Avenue, Box F-0984, San Francisco CA 94143-0984; cmathews@ @ppi.ucsf.edu; phone: 415-476-7702; fax: 415-476-7389. Conflicts of Interest

Drs. Darrow, Lindqvist, Penninx, Delucchi, Wolkowitz and Mathews and Ms. Verhoeven and Ms. Révész report no financial relationships with commercial interests. 


\section{Keywords}

telomere length; depressive disorders; anxiety disorders; psychosis; post-traumatic stress disorder; bipolar disorders

\section{Introduction}

Psychiatric disorders place a heavy psychological disease burden on patients and are associated with increased risk of serious medical conditions and early mortality. Metaanalyses show that individuals with psychiatric disorders are more likely to suffer from cardiovascular disease, stroke, dementia, diabetes, and obesity(1-4), conditions that are generally considered aging-related as their prevalence increases steeply with age. Although some of the increased risk may be explained by lifestyle differences, as persons with psychiatric disorders are more likely to smoke, drink alcohol, eat poorly and exercise less(5), associations between psychiatric status and medical morbidity remain significant after adjusting for these factors(2). These findings suggest that physiological mechanisms play an important role in the relationship between psychiatric disorders and physical health, leading to the hypothesis that this relationship may be mediated by accelerated cellular aging(6).

One well-studied indicator of cellular aging is telomere length (TL). Telomeres are repetitive DNA-protein complexes with repeated TTAGGG nucleotide sequences that cap the end of chromosomes and protect them from damage. TL is largely genetically determined, but also depends on developmental and environmental factors (7). Telomeres are not fully replicated during every cell division, causing mitotic cells to become progressively shorter over the lifespan if not acted upon by telomerase, the major telomere-lengthening enzyme(8). Physiological disturbances (e.g., increased inflammation and oxidative stress) thought to be important in the development of some psychiatric disorders $(6,9)$, may also accelerate telomere shortening $(10,11)$

TL is typically measured in leukocytes (LTL). Numerous epidemiological studies have reported associations between shorter LTL and somatic conditions (e.g., cardiovascular disease(12), obesity(13), diabetes(14)). However, it is unclear whether telomere shortening is a cause of deleterious effects or a marker of cumulative exposure to cytotoxic environments(15). Stem cells with critically shortened telomeres may undergo apoptosis or genomic instability, leading to loss of reparative function(16). Also, senescent lymphocytes can hypersecrete inflammatory cytokines, promoting certain diseases and leading to further telomere shortening(15). Due to the progressive shortening of TL with age and association with diseases of aging, TL can be seen as an index of biological aging. If accelerated telomere shortening is associated with certain psychiatric disorders, it might help explain the relationship between medical morbidity and those disorders, even though causality remains in question.

Multiple studies have examined the relationship between LTL and psychiatric disorders with mixed results(17-19). This inconsistency is likely to have several causes, including differences in methodology, demographic composition of the participant groups (e.g., age, sex) and small sample sizes. Study sample sizes have ranged from nine to over 1000 
participants, but many studies had small samples $(n<100)$. Further, the age of participants ranged from 22 to 93. For example, two studies with a similar design found a LTL difference, relative to controls, for adult patients with major depressive disorder (MDD; mean age $=42)(20)$, but this difference was not seen in a study of late-life MDD (mean age $=71)(21)$. Finally, technological approaches to extracting DNA and measuring TL may also contribute to inconsistent results $(22,23)$.

Given the observed association between shorter LTL and psychiatric disorders in some studies, additional investigation is needed. The goal of this study was to comprehensively examine the relationship between LTL and psychiatric disorders using meta-analysis to guide future research efforts, including determining whether investigations into potential biological or causal relationships between LTL and psychiatric illness are merited. In subgroup analysis and meta-regression, we also explored whether type of psychiatric disorder (e.g., depressive, psychotic, or anxiety disorders) and between-study differences (e.g., TL assessment method, sex and participants' age) are differentially associated with shortened telomeres.

\section{Methods}

The current study followed the preferred reporting items for systematic reviews and metaanalyses (PRISMA) statement for meta-analyses(24).

\section{Literature Search}

The search, review of abstracts, and abstraction of data were conducted by postdoctoral research fellows (SD and DL) and graduate students (DR and JV) supervised by experts in meta-analysis, psychiatric disorders, and telomere measurement (KD, BP, OW \& CM). We followed a three-stage approach to identify appropriate articles. First, in May 2014, PubMed, PsychInfo and Embase databases were searched using terms related to telomeres and psychiatric disorders (see Table 1 for full search strategy). Publication year ranged from 1974 to 2014. Second, we identified additional articles by reviewing online tables of contents for recent issues of journals known to publish relevant articles through November 2014. Third, all authors of articles included in the meta-analysis, as well as those known to be interested in similar research, were contacted to obtain unpublished data pertinent to this analysis.

Two independent raters (SD/DL or DR/JV) screened each abstract regarding the inclusion and exclusion criteria (described below). Discrepancies were resolved by a third author (OW or CM). Articles that passed the initial screening were reviewed in full (see Data Extraction) following the same method to make the final determination.

Inclusion and exclusion criteria-Articles had to describe original research, be conducted in adult humans, measure LTL, examine the relationship between LTL and a psychiatric disorder, and include a non-psychiatric control group (included both independent and matched group designs). Studies were excluded if LTL was measured post-mortem, in persons below age 18, and if blood collection for LTL measurement and diagnostic assessment occurred at separate time points (i.e., longitudinal studies in which diagnostic 
status was determined in a different wave than blood collection). Studies that examined dementias or developmental disabilities were excluded, as these disorders are associated with known structural brain and other systemic abnormalities, potentially confounding the analyses. Substance use disorders were also excluded, as substances may have a direct effect on telomere length independent of any relationship between vulnerability to substance misuse and telomere length. Presence of a psychiatric disorder was defined using DSM-IV or ICD-10 criteria for a current (i.e., within the past year) Axis I disorder. In order to examine the relationship between LTL and psychiatric disorders rather than dimensional psychiatric symptoms, we excluded studies that only employed continuous measures of psychiatric symptoms rather than diagnostic criteria. We included studies in which the primary objective was not necessarily to examine the relationship between a psychiatric disorder and TL (e.g., a study examined the relationship between TL and lithium response) if one of the groups was formed based on the presence of a psychiatric diagnosis. When comorbid psychiatric symptoms and/or disorders were present, we used primary diagnoses only to categorize participants.

\section{Data Extraction}

Data were independently abstracted by two members of the research team. The coders initially agreed on $96 \%$ of the data points. Data on the following variables were collected: study design, telomere assay method, LTL (mean and SD), sample size, diagnosis, age, sex, and other covariates (e.g., body mass index) included in the original analyses.

When studies included multiple groups that met criteria for a psychiatric disorder (e.g., one group met criteria for MDD and the other for bipolar disorder (BD)), the data were abstracted separately for these groups whenever possible. In studies with multiple psychiatric case groups and only one healthy control group, the same control group was used for each case group; the data from these cases are not completely independent.

Telomere assay method-Studies were included regardless of the method used to measure LTL and the method was recorded; methods included Quantitative fluorescence in situ hybridization (FISH), Quantitative polymerase chain reaction (PCR or Q-PCR), and Southern Blot.

Leukocyte telomere length data-If LTL data were not normally distributed and the researchers used log transformations to meet the assumptions of normality, the logtransformed data were used.

Covariates-We noted how studies controlled for variables known to be related to TL (e.g., age, sex). Studies were classified as "adjusted" for covariates if they 1) employed matched group designs, 2) statistically adjusted for covariates, or 3) both. Studies were classified as "unadjusted" if they employed independent groups designs and did not statistically control for covariates. Wherever possible, we used data that were statistically adjusted for covariates determined a priori by the researchers (i.e., if a study included multiple sequential analyses examining additional covariates, we abstracted the adjusted data 
from the analysis with the fewest covariates) to attempt to abstract data as similar as possible across studies.

\section{Statistical Analyses}

Statistical analyses were performed using RevMan version 5.3(25) and SPSS version 19. The random-effects model was employed because we hypothesized that there would be significant variations in effect sizes as a result of the diverse study designs. The means, standard deviations, and sample sizes for each group were used to calculate a standardized mean difference effect size (adjusted Hedge's $g$ ) for each study and the inverse variance method was used to combine the results across studies. A Hedge's $g$ is interpreted as the difference between the mean LTL (independent of the units of measurement) for the two groups divided by the pooled standard deviation of the groups (e.g., -0.5 indicates the mean LTL of the psychiatric disorder group was 0.5 standard deviations smaller than the control group mean LTL). Effect sizes are described according to the following standards: 0.2 is small, 0.5 is moderate, and 0.8 is large(26). Heterogeneity was evaluated using the Higgins $\mathrm{I}^{2}$ statistic and the Cochran's Q test(27). $\mathrm{I}^{2}$ represents the proportion of observed variance that reflects true (rather than chance) differences in effect size. A significant $Q$ test (i.e., $\mathrm{p}<0.05$ ) indicates that observed differences in effect size are not likely due to chance alone. Thus, significant, high heterogeneity indicates that some variable(s) (i.e., between-study difference) is/are causing different effect size estimates. Additionally, the funnel plot was examined to assess for publication bias based on the assumption that studies employing smaller samples with negative results are less likely to be published(27). A significant Egger test $(\mathrm{p}<0.01)$ indicates possible publication bias.

To explore possible sources of heterogeneity, we conducted subgroup analyses to compare effects sizes of studies employing different telomere assays, psychiatric disorders, and methods to adjust for covariates. Finally, meta-regression was used to identify potential moderators of the effect size (i.e., age, sex, assay method, psychiatric disorder). Sample size was used as a weight in all analyses.

\section{Results}

\section{Systematic Review}

The literature search resulted in 561 unique abstracts; eight recently published articles were also identified (see Figure 1). Forty-five articles passed initial screening and were reviewed in full. Of these, 27 articles met all inclusion criteria. These articles described studies examining the relationship between LTL and multiple psychiatric disorders (e.g., MDD, BD, panic disorder, schizophrenia, post-traumatic stress disorder [PTSD]); these disorders were collapsed into five categories (i.e., depressive disorders, bipolar disorders, anxiety disorders, psychotic disorders, and PTSD; see Table 2). Twenty-four authors responded to inquiries regarding unpublished data; three were in the process of publishing their new data and did not wish it to be included in the meta-analysis. The other 21 were not aware of unpublished data. Thus, all data included came from published articles, including one published abstract(47). 
Two articles $(35,52)$ reported studies using both independent and matched groups. The samples from Kao and colleagues(35) did not completely overlap and the data from both studies were used. However, in Zhang and colleagues'(52) article, all of the participants in the matched sample analyses were also included in the independent group analyses; therefore, only data from the matched group analyses were included. Further, one article reported separate analyses for a bipolar group and a schizophrenia group, compared to different control groups(40); one article reported separate analyses for a depressed group and an anxiety group, compared to the same control group(42); and one article reported separate analyses for a depressed group, a bipolar group, and a bipolar plus anxiety group, all were matched and compared to the same control group(46). The data from all of these analyses were included as separate studies.

Thus, data from 32 studies (5,289 psychiatric cases and 9,538 controls) were included in the meta-analysis (Table 2). Specific data that were not included in the published articles but were necessary for the meta-analysis were obtained from authors of six articles (e.g., actual means and standard deviations of LTL when data were only reported in a figure).

\section{Meta-Analysis}

The overall meta-analysis demonstrated a significant medium effect size ( $g=-0.50$; CI: $-0.70,-0.30 ; \mathrm{p}<0.001)$, indicating that psychiatric disorders overall were associated with shorter LTL (Figure 2). The Cochran's $\mathrm{Q}$ test $\left(\chi^{2}=603.31, \mathrm{df}=31, \mathrm{p}<0.001\right)$ and high $\mathrm{I}^{2}$ (95\%) suggested substantial heterogeneity across studies, indicating that differences in study design or participant characteristics, not chance, caused differences in individual study effect sizes(53). The funnel plot (Figure 3) did not show noticeable asymmetry, suggesting that there was no evidence of publication bias.

Examining heterogeneity due to methodological variables-We next sub-grouped studies by whether they adjusted for covariates and by assay method (Table 3 ).

The overall test between the pooled estimates for the unadjusted and adjusted studies was not significant. Thus, all studies were included in subsequent analyses. The overall test for the subgroup analyses examining different TL assay methods was also not significant, indicating that inclusion of different methods of telomere measurement did not result in different effect sizes.

\section{Examining heterogeneity across different psychiatric disorders-Both the} subgroup analysis and examination of the forest plot (Figure 2) suggested that LTL was shorter for patients than controls for all included psychiatric disorders, and the difference in effect sizes between disorders was not significant (Table 3). Sub-group effect sizes for depressive disorders, PTSD and anxiety disorders were statistically significant (i.e., confidence intervals did not cross zero; $\mathrm{p}=0.004,0.003, \& 0.05$, respectively); those for psychotic and bipolar disorders were not significant. The PTSD sub-group had a large effect size $(-1.27)$ and depressive and anxiety disorders had moderate effect sizes $(-0.55$ and -0.53 , respectively). Psychotic disorders and bipolar disorder had comparatively smaller effect sizes ( -0.23 and -0.26 , respectively). 
Within each diagnostic subgroup, there was also evidence of significant heterogeneity $\left(\mathrm{I}^{2}>90 \%\right.$, Table 3$)$; the observed differences in effect sizes between studies in each disorder subgroup were more than expected by chance.

\section{Meta-regression}

Meta-regression was used to examine the effect of multiple potential moderators simultaneously. The predictor variables were assay method, type of psychiatric diagnosis, mean age, and proportion of female participants and effect size was the outcome variable. Both age and sex generally affect TL $(54,55)$, and were consistently reported across all studies, allowing us to examine their effects. The multivariate random-effects metaregression modeling age, sex, assay method and psychiatric diagnoses resulted in a significant effect size $(-0.50 ; \mathrm{CI}-0.71,-0.30)$ that replicated the global effect size calculated by the primary meta-analysis $(-0.50 ; \mathrm{CI}-0.70,-0.30)$. Including studies examining psychosis significantly decreased the overall effect size compared to including those on depressive disorders, and studies on PTSD significantly increased the overall effect size compared to including those on depressive disorders (see Table 4). Notably, age approached significance, indicating that studies with younger subjects decreased the effect size. However, the test of residual variance for the overall model was significant $\left(\chi^{2}=45.66\right.$, $\mathrm{df}=23, p=0.003$ ), indicating that the heterogeneity of effect size across studies was not adequately explained by the covariates included in the meta-regression. Thus, the observed effects of the individual predictors may be related to a variable not specified in the current model.

\section{Discussion}

This study examined the relationship between cellular aging as indicated by LTL and a wide range of psychiatric disorders, including 14,827 participants. The global meta-analysis effect size was significant $(-0.50)$, indicating, as hypothesized, that shortened LTL is seen across many psychiatric disorders, despite the high level of heterogeneity between individual studies. The meta-regression confirmed the global effect size estimate, and indicated that the heterogeneity was not adequately explained by simultaneous consideration of differences between studies in method, assay, age, gender, and psychiatric disorder. Of these, perhaps the most interesting to examine further is psychiatric diagnosis.

We found significant effect sizes for depressive disorders, PTSD and anxiety disorders. Overall, there was no significant difference in the effect size estimates between the different disorder subgroups. However, the number of studies was small for some of the disorders, thus an additional study could clearly change the outcome of sub-group analyses. Therefore, further studies are needed to clarify whether meaningful differences in LTL by diagnosis exist. The results of the meta-regression provide some support for further study of potential differences in effect size between psychiatric disorders. The effect size was moderated by different disorders, although additional sources of heterogeneity of effect size may be identified that change this relationship.

In addition to the value derived from identifying differences between disorders, finding evidence of telomere shortening across disorders is interesting in the current context of 
psychiatric research. Given the high prevalence of comorbidity between psychiatric disorders(56), heterogeneity within disorders, and the lack of robust biological underpinnings for current diagnostic constructs, psychiatric research is moving away from disorder-based constructs and increasingly trying to elucidate trans-diagnostic mechanisms(57). There is now emerging evidence to suggest that several currently defined psychiatric disorders share a common underlying genetic etiology(58). Thus, individual categorical psychiatric diagnoses are unlikely to be either necessary or sufficient for LTL shortening to be observed.

Although this meta-analysis focused on psychiatric diagnoses, there is a growing literature suggesting that chronic psychological stress and histories of repeated childhood adverse experiences (even in the absence of a formal psychiatric diagnosis) may be related to shortened LTL $(17,59)$. Given the relationship between chronic psychological stress and/or childhood adversity and psychiatric illness $(60,61)$, future research should examine whether these experiences mediate the relationship between psychiatric diagnosis and LTL observed in our data. Future studies could test this hypothesis, perhaps by measuring history, chronicity, and severity of childhood adversity, as well as perceived psychological stress, and LTL in individuals across a variety of psychiatric diagnoses. Potential biological mechanisms of telomere shortening, which may be seen across psychiatric diagnoses, include excessive immune cell mitosis (as may be seen in repeated clonal expansion of leukocytes), increased oxidative stress and inflammation, decreased brain growth factors, and imbalances in metabolic factors, the hypothalamus-pituitary-adrenal axis, and autonomic nervous system functioning(62-65).

\section{Strengths and Limitations}

Strengths of this meta-analysis are the large total sample $(\mathrm{N}=14,827)$ and the comparison of LTL across multiple disorders. We were able to explore and control for possible causes of heterogeneity using meta-regression, allowing a more accurate determination of the relationship of LTL and psychiatric disorder. However, we cannot rule out the influence of comorbid psychiatric or medical disorders on the effect sizes. Most of the samples included here involved participants with comorbid symptoms or diagnoses (e.g., anxiety and depression), with medical illnesses or taking a variety of medications. In addition, we were not able to examine the effects of other potential moderators, including substance use, exercise, body mass index, age of onset or the duration and severity of the psychiatric disorders since these variables were not reported consistently across studies. The results of the meta-regression suggest that while age and diagnosis contribute, covariates other than age, sex, assay method and diagnosis also contribute substantially. Furthermore, the covariates that were adjusted for within the primary studies differed (e.g., some primary studies adjusted for BMI while others did not). Thus we cannot rule out other moderators of the relationship between TL and psychiatric disorders.

Importantly, the cross-sectional nature of the studies reviewed here limited our ability to draw causal conclusions regarding the association between telomere shortening and psychiatric disorders. While most authors suggest that telomere shortening is a consequence of prolonged physiological dysregulation, another possibility is that short telomeres antedate 
the development of psychiatric disorders. Of note, a recent meta-analysis in almost 20,000 subjects estimated the heritability of LTL at 70\%(7). Another recent study found that girls at high genetic risk for MDD (by virtue of having mothers with MDD) had short salivary TL before any occurrence of depressive episodes(66). Longitudinal studies with measures of TL and psychiatric disorder status at multiple time points are needed to elucidate the causal relation. Importantly, the present data in no way substantiate or refute a causal relationship between telomere shortness and medical illness or mortality in individuals with psychiatric illnesses. Further clarity regarding the relationship between telomere length and medical illness and mortality is also needed(67). Finally, new publications in this area continue to be published, and the results of this meta-analysis should only be interpreted on the basis of data available through November 2014.

\title{
Conclusions
}

This meta-analysis shows that LTL shortening is found across various psychiatric disorders, and also raises the possibility that specific types of psychiatric disorders may be differentially associated with shorter LTL. Future research should focus on identifying possible common mechanisms of telomere shortening across disorders, and on elucidating potential differences in telomere shortening between psychiatric disorders.

\section{Acknowledgments}

\author{
Source of Funding \\ Drs. Darrow and Mathews were supported by NIH R01 MH096767. \\ Dr. Penninx, Ms. Verhoeven and Ms. Révész are supported by NWO-VICI 91811602. \\ Dr. Lindqvist was supported by The Swedish Society of Medicine (SLS-244821), the Swedish Research Council \\ (registration number 2015-00387), Marie Sklodowska Curie Actions, Cofund, Project INCA 600398, the Sjobring \\ Foundation, OM Persson Foundation and the province of Scania (Sweden) state grants (ALF). \\ Dr. Wolkowitz was supported by NIMH R01 MH083784, DOD W81XWH-10-1-0021, the O'Shaughnessy \\ Foundation and the Tinberg Family. \\ We gratefully acknowledge the long-term scientific collaborations with Drs. Elissa S. Epel, Elizabeth H. Blackburn, \\ Jue Lin and Victor I. Reus.
}

\section{Acronyms used}

\author{
TL \\ telomere length \\ LTL leukocyte telomere length \\ MDD major depressive disorder \\ PTSD post-traumatic stress disorder \\ BD bipolar disorders \\ DSM-IV Diagnostic and Statistical Manual of Mental Disorders, $4^{\text {th }}$ \\ edition \\ ICD-10 International Classification of Diseases, $10^{\text {th }}$ edition
}


FISH

PCR or Q-PCR

df

BMI

SMD

SE
Quantitative fluorescence in situ hybridization

Quantitative polymerase chain reaction

degrees of freedom

body mass index

standard mean difference

standard error

\section{References}

1. Viron MJ, Stern TA. The impact of serious mental illness on health and healthcare. Psychosomatics. 2010; 51(6):458-465. [PubMed: 21051676]

2. Penninx BWJH, Milaneschi Y, Lamers F, Vogelzangs N. Understanding the somatic consequences of depression: biological mechanisms and the role of depression symptom profile. BMC Med. 2013; 11(129)doi: 10.1186/1741-7015-11-129

3. D'Mello MJ, Ross SA, Briel M, Anand SS, Gerstein H, Pare G. Association between shortened leukocyte telomere length and cardiometabolic outcomes: systematic review and meta-analysis. Circ Cardiovasc Genet. 2015; 8(1):82-90. [PubMed: 25406241]

4. Cuijpers P, Vogelzangs N, Twisk J, Kleiboer A, Li J, Penninx BW. Comprehensive Meta-Analysis of Excess Mortality in Depression in the General Community Versus Patients With Specific Illnesses. American Journal of Psychiatry. 2014; 171(4):453-462. [PubMed: 24434956]

5. van Gool CH, Kempen GIJM, Bosma H, van Boxtel MPJ, Jolles J, van Eijk JTM. Associations between lifestyle and depressed mood: longitudinal results from the Maastricht Aging Study. Am J Public Health. 2007; 97(5):887-894. [PubMed: 16735630]

6. Wolkowitz OM, Epel ES, Reus VI, Mellon SH. Depression gets old fast: Do stress and depression accelerate cell aging? Depression and Anxiety. 2010; 27(4):327-338. [PubMed: 20376837]

7. Broer L, Codd V, Nyholt DR, Deelen J, Mangino M, Willemsen G, Albrecht E, Amin N, Beekman M, de Geus EJ, Henders A, Nelson CP, Steves CJ, Wright MJ, de Craen AJ, Isaacs A, Matthews M, Moayyeri A, Montgomery GW, Oostra BA, Vink J, Spector TD, Slagboom PE, Martin NG, Samani NJ, van Duijn CM, Boomsma DI. Meta-analysis of telomere length in 19713 subjects reveals high heritability, stronger maternal inheritance and a paternal age effect. Eur J Hum Genet. 2013

8. Blackburn EH. Switching and signaling at the telomere. Cell. 2001; 106(6):661-673. [PubMed: 11572773]

9. Rawdin BJ, Mellon SH, Dhabhar FS, Epel ES, Puterman E, Su Y, Burke HM, Reus VI, Rosser R, Hamilton SP, Nelson JC, Wolkowitz OM. Dysregulated relationship of inflammation and oxidative stress in major depression. Brain Behav Immun. 2013; 31:143-52. [PubMed: 23201587]

10. Révész D, Verhoeven JE, Milaneschi Y, de Geus EJCN, Wolkowitz OM, Penninx BWJH. Dysregulated physiological stress systems and accelerated cellular aging. Neurobiology of Aging. 2013

11. Kiecolt-Glaser JK, Epel ES, Belury MA, Andridge R, Lin J, Glaser R, Malarkey WB, Hwang BS, Blackburn E. Omega-3 fatty acids, oxidative stress, and leukocyte telomere length: A randomized controlled trial. Brain, Behavior, and Immunity. 2013; 28:16-24.

12. Fitzpatrick AL, Kronmal RA, Gardner JP, Psaty BM, Jenny NS, Tracy RP, Walston J, Kimura M, Aviv A. Leukocyte telomere length and cardiovascular disease in the cardiovascular health study. Am J Epidemiol. 2007; 165(1):14-21. [PubMed: 17043079]

13. Valdes AM, Andrew T, Gardner JP, Kimura M, Oelsner E, Cherkas LF, Aviv A, Spector TD. Obesity, cigarette smoking, and telomere length in women. The Lancet. 2005; 366(9486):662-664.

14. Sampson MJ, Winterbone MS, Hughes JC, Dozio N, Hughes DA. Monocyte telomere shortening and oxidative DNA damage in type 2 diabetes. Diabetes Care. 2006; 29(2):283-289. [PubMed: 16443874] 
15. Effros RB. Kleemeier Award Lecture 2008--the canary in the coal mine: telomeres and human healthspan. J Gerontol A Biol Sci Med Sci. 2009; 64(5):511-515. [PubMed: 19228779]

16. Nalapareddy K, Jiang H, Guachalla Gutierrez LM, Rudolph KL. Determining the influence of telomere dysfunction and DNA damage on stem and progenitor cell aging: what markers can we use? Exp Gerontol. 2008; 43(11):998-1004. [PubMed: 18817864]

17. Starkweather AR, Alhaeeri AA, Montpetit A, Brumelle J, Filler K, Montpetit M, Mohanraj L, Lyon DE, Jackson-Cook CK. An integrative review of factors associated with telomere length and implications for biobehavioral research. Nurs Res. 2014; 63(1):36-50. [PubMed: 24335912]

18. Kinser PA, Lyon DE. Major depressive disorder and measures of cellular aging: an integrative review. Nurs Res Pract. 2013; 2013:469070. [PubMed: 23691300]

19. Lindqvist D, Epel ES, Mellon SH, Penninx BW, Revesz D, Verhoeven JE, Reus VI, Lin J, Mahan L, Hough CM, Rosser R, Bersani FS, Blackburn EH, Wolkowitz OM. Psychiatric disorders and leukocyte telomere length: Underlying mechanisms linking mental illness with cellular aging. Neurosci Biobehav Rev. 2015; 55:333-364. [PubMed: 25999120]

20. Verhoeven JE, Revesz D, Epel ES, Lin J, Wolkowitz OM, Penninx BWJH. Major depressive disorder and accelerated cellular aging: results from a large psychiatric cohort study. Mol Psychiatry. 2014; 19(8):895-901. [PubMed: 24217256]

21. Schaakxs R, Verhoeven JE, Oude Voshaar RC, Comijs HC, Penninx BWJH. Leukocyte Telomere Length and Late-Life Depression. Am J Geriatr Psychiatry. 2014

22. Aubert G, Hills M, Lansdorp PM. Telomere length measurement-caveats and a critical assessment of the available technologies and tools. Mutat Res. 2012; 730(1-2):59-67. [PubMed: 21663926]

23. Dlouha D, Maluskova J, Kralova Lesna I, Lanska V, Hubacek JA. Comparison of the relative telomere length measured in leukocytes and eleven different human tissues. Physiol Res. 2014; 63(Suppl 3):S343-50. [PubMed: 25428739]

24. Moher D, Liberati A, Tetzlaff J, Altman DG. Preferred reporting items for systematic reviews and meta-analyses: the PRISMA statement. J Clin Epidemiol. 2009; 62(10):1006-12. [PubMed: 19631508]

25. Colaboration, T.C. Review Manager (RevMan), in Version 5.3 for Windows. The Nordic Cochrane Center; Copenhagen: 2014.

26. Cohen, J. Statistical Power Analysis for the Behavioral Sciences. 2. Lawrence Erlbaum Associates; 1988.

27. Borenstein, M.; Hedges, LV.; Higgins, JPT.; Rothstein, HR. Introduction to Meta-analysis. West Sussex, United Kingdom: John Wiley \& Sons, Ltd; 2009.

28. Elvsåshagen T, Vera E, Bøen E, Bratlie J, Andreassen OA, Josefsen D, Malt UF, Blasco MA, Boye B. The load of short telomeres is increased and associated with lifetime number of depressive episodes in bipolar II disorder. Journal of Affective Disorders. 2011; 135(1-3):43-50. [PubMed: 21880373]

29. Fernandez-Egea E, Bernardo M, Heaphy CM, Griffith JK, Parellada E, Esmatjes E, Conget I, Nguyen L, George V, Stöppler H, Kirkpatrick B. Telomere length and pulse pressure in newly diagnosed, antipsychotic-naive patients with nonaffective psychosis. Schizophrenia Bulletin. 2009; 35(2):437-442. [PubMed: 19279086]

30. Garcia-Rizo C, Fernandez-Egea E, Miller BJ, Oliveira C, Justicia A, Griffith JK, Heaphy CM, Bernardo M, Kirkpatrick B. Abnormal glucose tolerance, white blood cell count, and telomere length in newly diagnosed, antidepressant-naïve patients with depression. Brain, Behavior, and Immunity. 2013; 28:49-53.

31. Hartmann N, Boehner M, Groenen F, Kalb R. Telomere length of patients with major depression is shortened but independent from therapy and severity of the disease. Depression and Anxiety. 2010; 27(12):1111-1116. [PubMed: 21053332]

32. Hoen PW, de Jonge P, Ya Na B, Farzaneh-Far R, Epel E, Lin J, Blackburn E, Whooley MA. Depression and leukocyte telomere length in patients with coronary heart disease: Data from the Heart and Soul Study. Psychosomatic Medicine. 2011; 73(7):541-547. [PubMed: 21597035]

33. Jergovic M, Tomicevic M, Vidovic A, Bendelja K, Savic A, Vojvoda V, Rac D, Lovric-Cavar D, Rabatic S, Jovanovic T, Sabioncello A. Telomere shortening and immune activity in war veterans 
with posttraumatic stress disorder. Prog Neuropsychopharmacol Biol Psychiatry. 2014; 54:275-83. [PubMed: 24977331]

34. Kananen L, Surakka I, Pirkola S, Suvisaari J, Lönnqvist J, Peltonen L, Ripatti S, Hovatta I. Childhood adversities are associated with shorter telomere length at adult age both in individuals with an anxiety disorder and controls. PLoS ONE. 2010; 5(5)

35. Kao HT, Cawthon RM, DeLisi LE, Bertisch HC, Ji F, Gordon D, Li P, Benedict MM, Greenberg WM, Porton B. Rapid telomere erosion in schizophrenia. Molecular Psychiatry. 2008; 13(2):118119. [PubMed: 18202693]

36. Ladwig KH, Brockhaus AC, Baumert J, Lukaschek K, Emeny RT, Kruse J, Codd V, Hafner S, Albrecht E, Illig T, Samani NJ, Wichmann HE, Gieger C, Peters A. Posttraumatic stress disorder and not depression is associated with shorter leukocyte telomere length: findings from 3,000 participants in the population-based KORA F4 study. PLoS One. 2013; 8(7):e64762. [PubMed: 23843935]

37. Lima IM, Barros A, Rosa DV, Albuquerque M, Malloy-Diniz L, Neves FS, Romano-Silva MA, de Miranda DM. Analysis of telomere attrition in bipolar disorder. J Affect Disord. 2014; 172c:4347. [PubMed: 25451394]

38. Lung FW, Chen NC, Shu BC. Genetic pathway of major depressive disorder in shortening telomeric length. Psychiatr Genet. 2007; 17(3):195-9. [PubMed: 17417064]

39. Malan S, Hemmings S, Kidd M, Martin L, Seedat S. Investigation of telomere length and psychological stress in rape victims. Depression and Anxiety. 2011; 28(12):1081-1085. [PubMed: 22065550]

40. Mansour H, Chowdari K, Fathi W, Elassy M, Ibrahim I, Wood J, Bamne M, Tobar S, Yassin A, Salah H, Elsayed H, Eissa A, El-Boraie H, Ibrahim NE, Elsayed M, El-Bahaei W, Gomaa Z, ElChennawi F, Nimgaonkar VL. Does telomere length mediate associations between inbreeding and increased risk for bipolar I disorder and schizophrenia? Psychiatry Research. 2011; 188(1):129132. [PubMed: 21300409]

41. Martinsson L, Wei Y, Xu D, Melas PA, Mathe AA, Schalling M, Lavebratt C, Backlund L. Longterm lithium treatment in bipolar disorder is associated with longer leukocyte telomeres. Transl Psychiatry. 2013; 3:e261. [PubMed: 23695236]

42. Needham BL, Mezuk B, Bareis N, Lin J, Blackburn EH, Epel ES. Depression, anxiety and telomere length in young adults: evidence from the National Health and Nutrition Examination Survey. Mol Psychiatry. 2014

43. Nieratschker V, Lahtinen J, Meier S, Strohmaier J, Frank J, Heinrich A, Breuer R, Witt SH, Nothen MM, Rietschel M, Hovatta I. Longer telomere length in patients with schizophrenia. Schizophr Res. 2013; 149(1-3):116-120. [PubMed: 23870621]

44. O’Donovan A, Epel E, Lin J, Wolkowitz O, Cohen B, Maguen S, Metzler T, Lenoci M, Blackburn E, Neylan TC. Childhood trauma associated with short leukocyte telomere length in posttraumatic stress disorder. Biological Psychiatry. 2011; 70(5):465-471. [PubMed: 21489410]

45. Rizzo LB, Do Prado CH, Grassi-Oliveira R, Wieck A, Correa BL, Teixeira AL, Bauer ME. Immunosenescence is associated with human cytomegalovirus and shortened telomeres in type I bipolar disorder. Bipolar Disorders. 2013; 15(8):832-838. [PubMed: 24021055]

46. Simon NM, Smoller JW, McNamara KL, Maser RS, Zalta AK, Pollack MH, Nierenberg AA, Fava M, Wong KK. Telomere Shortening and Mood Disorders: Preliminary Support for a Chronic Stress Model of Accelerated Aging. Biological Psychiatry. 2006; 60(5):432-435. [PubMed: 16581033]

47. Simon NM, Walton Z, Prescott J, Hoge E, Keshaviah A, Bui THE, Schwarz N, Dryman T, Ojserkis RA, Mischoulon D, Worthington J, DeVivo I, Fava M, Wong KK. A cross-sectional examination of telomere length and telomerase in a well-characterized sample of individuals with major depressive disorder compared to controls. Neuropsychopharmacology. 2013; 38:S322-S323. ((Simon N.M.; Walton Z.; Prescott J.; Hoge E.; Keshaviah A.; Bui T.H.E.; Schwarz N.; Dryman T.; Ojserkis R.A.; Mischoulon D.; Worthington J.; DeVivo I.; Fava M.; Wong K.-K.) Massachusetts General Hospital, Boston, United States).

48. Teyssier JR, Chauvet-Gelinier JC, Ragot S, Bonin B. Up-regulation of leucocytes genes implicated in telomere dysfunction and cellular senescence correlates with depression and anxiety severity scores. PLoS One. 2012; 7(11):e49677. [PubMed: 23185405] 
49. Verhoeven JE, Revesz D, van Oppen P, Epel ES, Wolkowitz O, Penninx BWJH. Anxiety Disorders and Accelerated Cellular Aging. Br J Psychiatry. 2014 (in press).

50. Wolkowitz OM, Mellon SH, Epel ES, Lin J, Dhabhar FS, Su Y, Reus VI, Rosser R, Burke HM, Kupferman E, Compagnone M, Nelson JC, Blackburn EH. Leukocyte telomere length in major depression: Correlations with chronicity, inflammation and oxidative - stress: Preliminary findings. PLoS ONE. 2011; 6(3)

51. Yu WY, Chang HW, Lin CH, Cho CL. Short telomeres in patients with chronic schizophrenia who show a poor response to treatment. J Psychiatry Neurosci. 2008; 33(3):244-7. [PubMed: 18592039]

52. Zhang L, Hu XZ, Benedek DM, Fullerton CS, Forsten RD, Naifeh JA, Li X, Li H, Benevides KN, Smerin S, Le T, Choi K, Ursano RJ. The interaction between stressful life events and leukocyte telomere length is associated with PTSD. Mol Psychiatry. 2014; 19(8):855-6. [PubMed: 24189343]

53. Higgins JPT, Thompson SG, Deeks JJ, Altman DG. Measuring inconsistency in meta-analyses. BMJ: British Medical Journal. 2003; 327(7414):557-560. [PubMed: 12958120]

54. Gardner M, Bann D, Wiley L, Cooper R, Hardy R, Nitsch D, Martin-Ruiz C, Shiels P, Sayer AA, Barbieri M, Bekaert S, Bischoff C, Brooks-Wilson A, Chen W, Cooper C, Christensen K, De Meyer T, Deary I, Der G, ez Roux A, Fitzpatrick A, Hajat A, Halaschek-Wiener J, Harris S, Hunt SC, Jagger C, Jeon HS, Kaplan R, Kimura M, Lansdorp P, Li C, Maeda T, Mangino M, Nawrot TS, Nilsson P, Nordfjall K, Paolisso G, Ren F, Riabowol K, Robertson T, Roos G, Staessen JA, Spector T, Tang N, Unryn B, van der Harst P, Woo J, Xing C, Yadegarfar ME, Park JY, Young N, Kuh D, Von Zglinicki T, Ben-Shlomo Y. Gender and telomere length: Systematic review and metaanalysis. Exp Gerontol. 2014; 51:15-27. [PubMed: 24365661]

55. Muezzinler A, Zaineddin AK, Brenner H. A systematic review of leukocyte telomere length and age in adults. Ageing Res Rev. 2013; 12(2):509-519. [PubMed: 23333817]

56. Kessler RC, Chiu WT, Demler O, Walters EE. Prevalence, Severity, and Comorbidity of 12-Month DSM-IV Disorders in the National Comorbidity Survey Replication. Archives of General Psychiatry. 2005; 62(6):617-627. [PubMed: 15939839]

57. Insel T, Cuthbert B, Garvey M, Heinssen R, Pine DS, Quinn K, Sanislow C, Wang P. Research domain criteria (RDoC): Toward a new classification framework for research on mental disorders. The American Journal of Psychiatry. 2010; 167(7):748-751. [PubMed: 20595427]

58. Lee SH, Ripke S, Neale BM, et al. Genetic relationship between five psychiatric disorders estimated from genome-wide SNPs. Nat Genet. 2013; 45(9):984-94. [PubMed: 23933821]

59. Price LH, Kao HT, Burgers DE, Carpenter LL, Tyrka AR. Telomeres and early-life stress: An overview. Biological Psychiatry. 2013; 73(1):15-23. [PubMed: 22831981]

60. Carr CP, Martins CM, Stingel AM, Lemgruber VB, Juruena MF. The role of early life stress in adult psychiatric disorders: a systematic review according to childhood trauma subtypes. J Nerv Ment Dis. 2013; 201(12):1007-20. [PubMed: 24284634]

61. Schutte NS, Malouff JM. The Relationship Between Perceived Stress and Telomere Length: A Meta-analysis. Stress Health. 2014

62. Wolkowitz OM V, Reus I, Mellon SH. Of sound mind and body: depression, disease, and accelerated aging. Dialogues Clin Neurosci. 2011; 13(1):25-39. [PubMed: 21485744]

63. Pandya CD, Howell KR, Pillai A. Antioxidants as potential therapeutics for neuropsychiatric disorders. Prog Neuropsychopharmacol Biol Psychiatry. 2013; 46:214-23. [PubMed: 23123357]

64. Joshi YB, Pratico D. Lipid peroxidation in psychiatric illness: overview of clinical evidence. Oxid Med Cell Longev. 2014; 2014:828702. [PubMed: 24868318]

65. Revesz D, Verhoeven JE, Milaneschi Y, de Geus EJ, Wolkowitz OM, Penninx BWJH. Dysregulated physiological stress systems and accelerated cellular aging. Neurobiol Aging. 2014; 35(6):1422-1430. [PubMed: 24439483]

66. Gotlib IH, LeMoult J, Colich NL, Foland-Ross LC, Hallmayer J, Joormann J, Lin J, Wolkowitz OM. Telomere length and cortisol reactivity in children of depressed mothers. Mol Psychiatry. 2014

67. Sanders JL, Newman AB. Telomere Length in Epidemiology: A Biomarker of Aging, Age-Related Disease, Both, or Neither? Epidemiologic Reviews. 2013; 35(1):112-131. [PubMed: 23302541] 


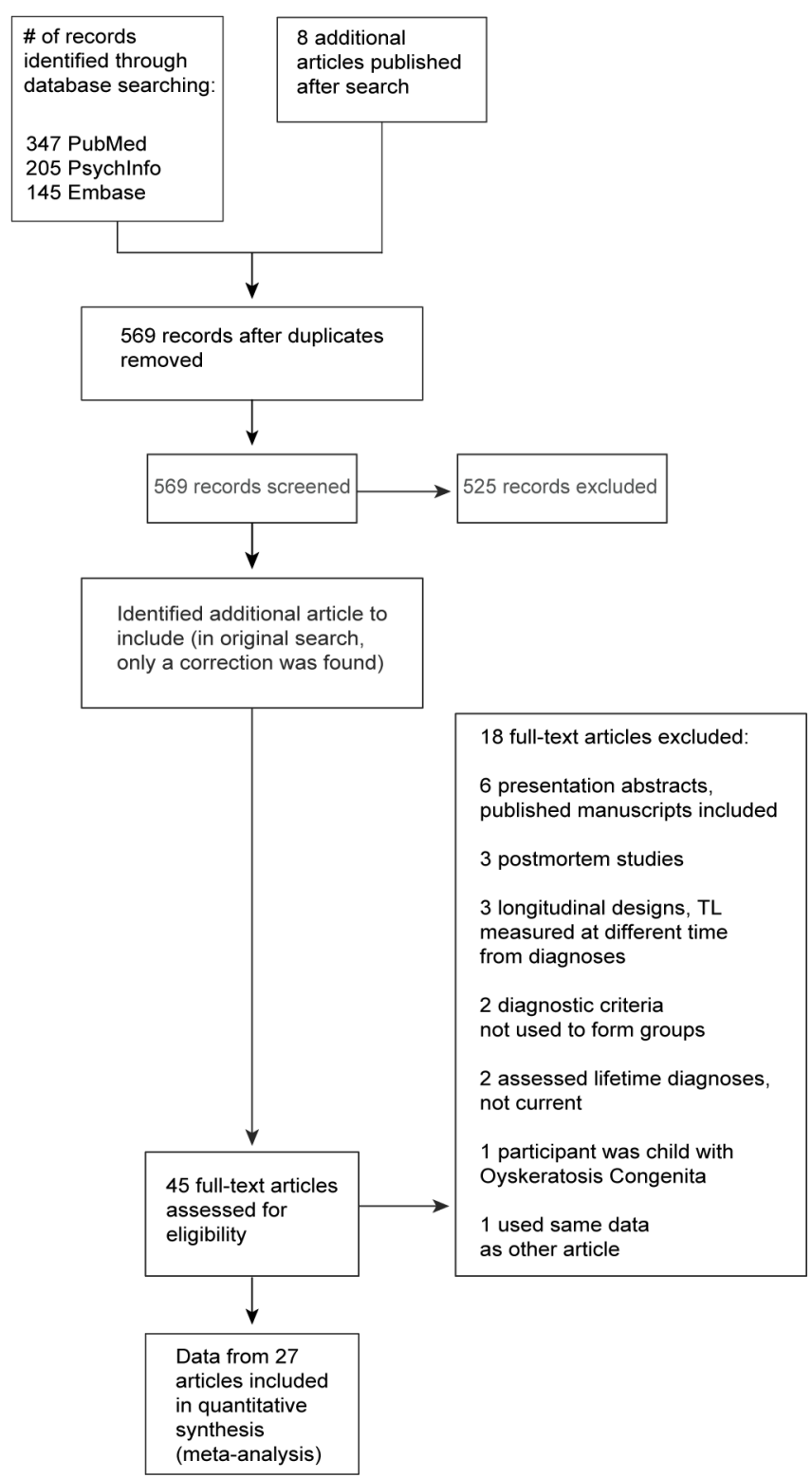

Figure 1.

Selection of Studies

Psychosom Med. Author manuscript; available in PMC 2017 September 01. 


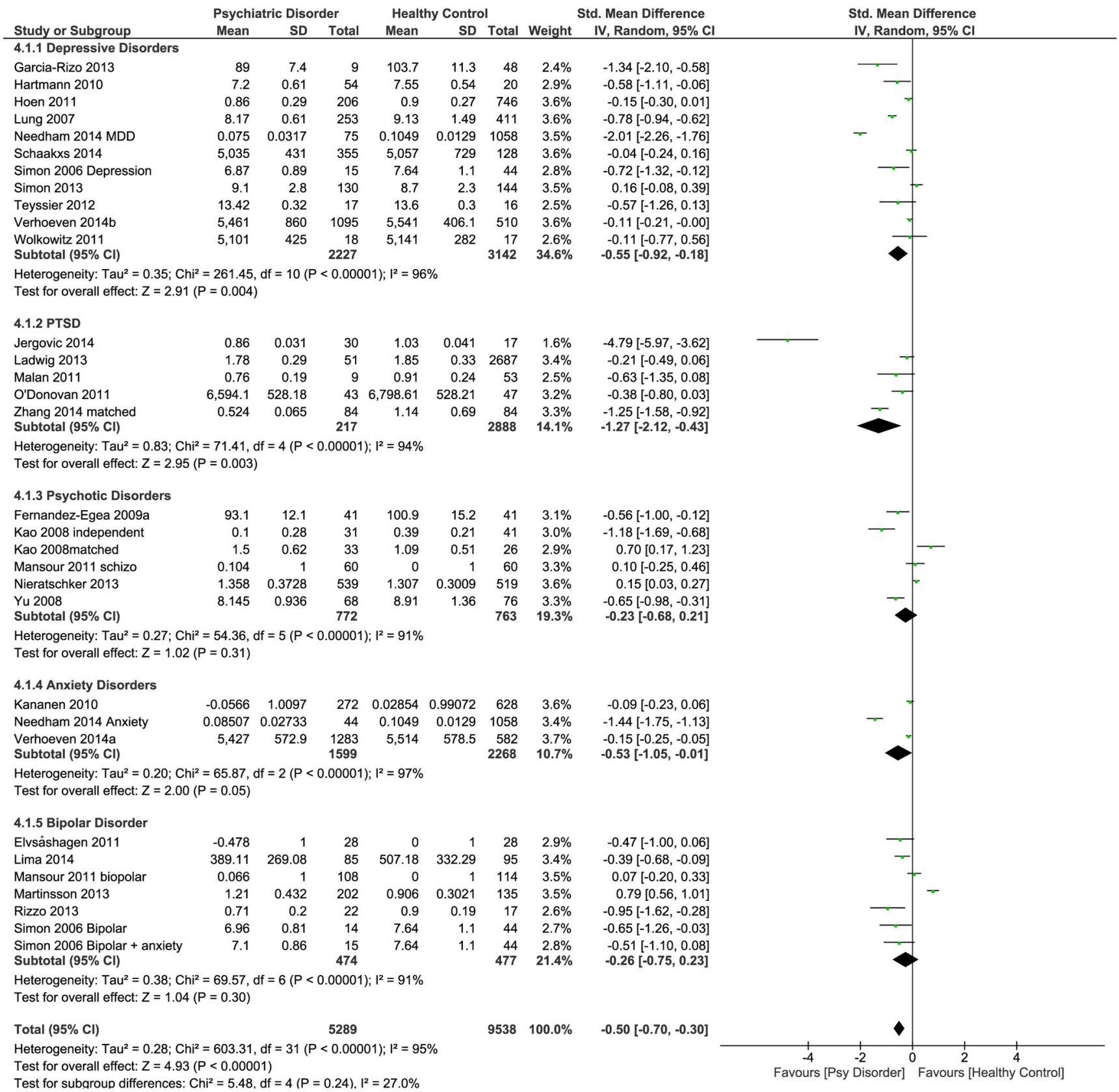

Figure 2.

Differences in effect sizes of studies examining different psychiatric disorders. 


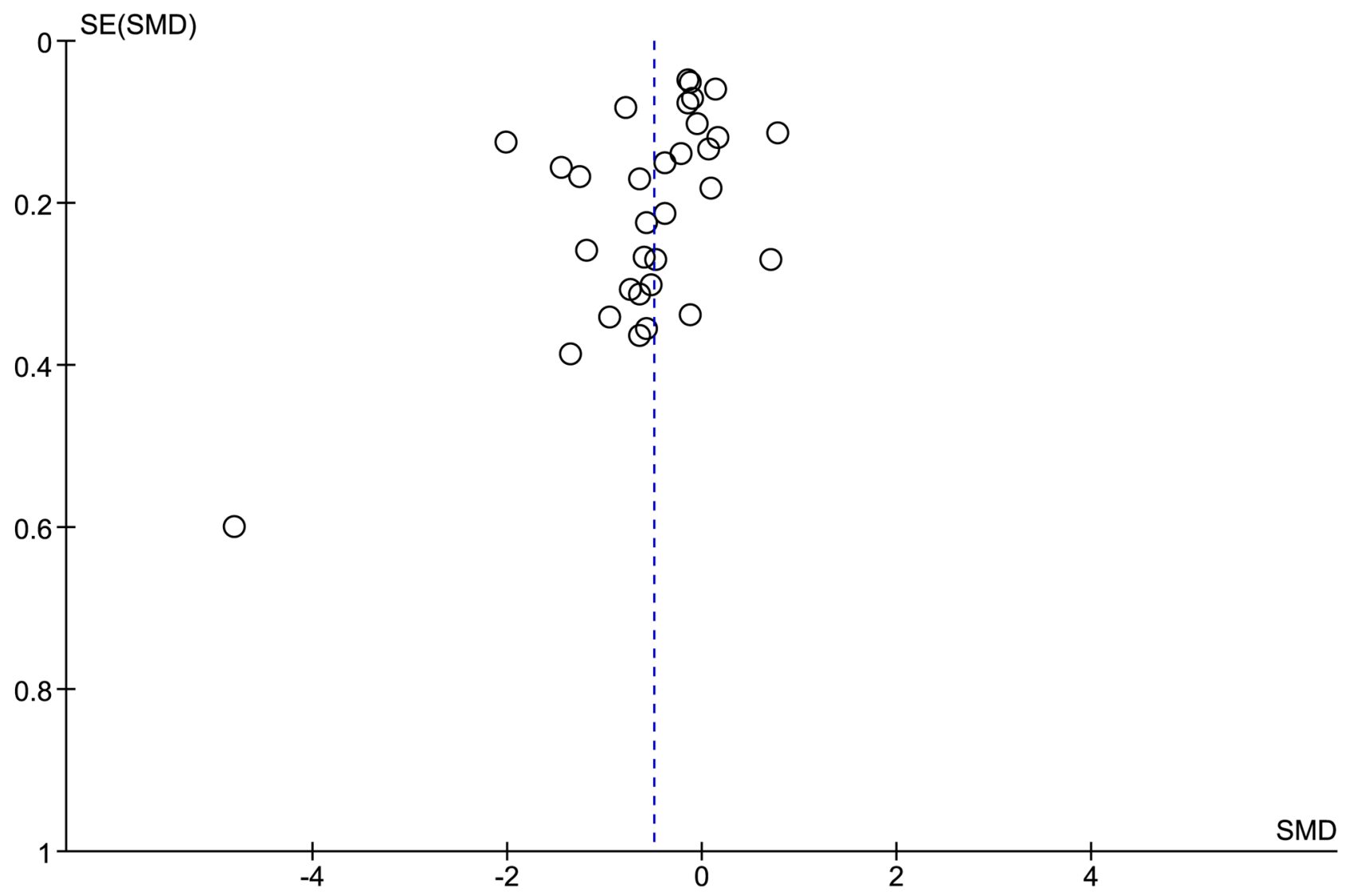

Figure 3.

Funnel Plot to examine publication bias.

Note: SMD=standard mean difference (Hedge's $g$ ); $\mathrm{SE}=$ standard error of standard mean difference. Egger test: -1.02 , CI $-3.89,1.84$, p=0.47 


\section{Table 1}

Search strategy

\begin{tabular}{cll}
\hline & Search terms & Abstracts found \\
\hline PubMed & (Telomere[MeSH Terms]) AND mental disorders[MeSH Terms] & 341 \\
& (Telomere shortening[MeSH Terms]) AND mental disorders[MeSH Terms] & 21 (15 duplicates) \\
& (Telomere shortening[MeSH Terms]) AND mood disorders[MeSH Terms] & 3 (all duplicates) \\
PsycInfo & su(mental disorders) AND ti(telomere) OR ab(telomere) 1 & 205 \\
subtotal & & 507 (45 duplicates) \\
Embase & Used following: "map to preferred term in Emtree" and "limit to terms indexed as major focus" & \\
& 'telomere'/exp AND 'mental disease'/exp & 140 \\
& 'mental disease'/exp AND 'telomere shortening'/exp & 15 \\
Total & & 565 (97 duplicates) \\
\hline
\end{tabular}

1 automatically includes plural form 


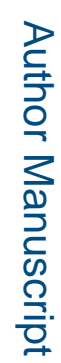

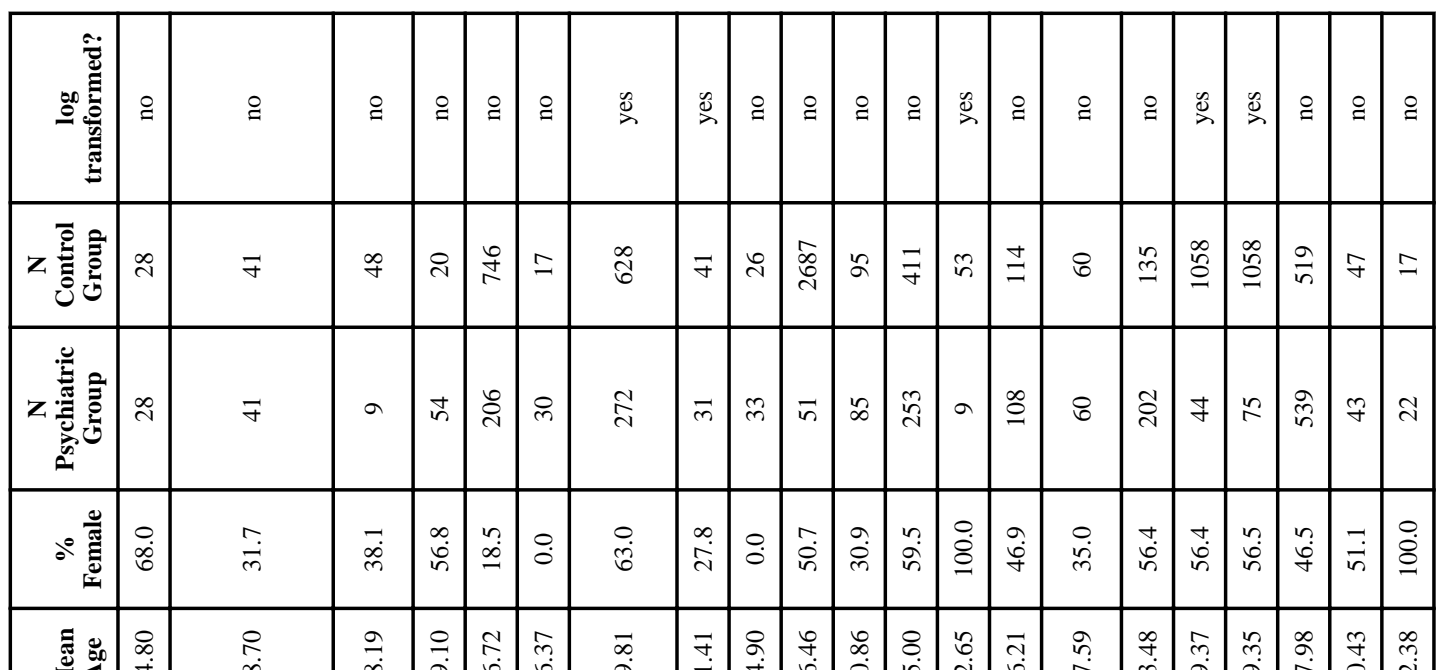

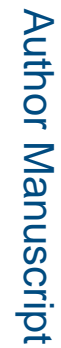

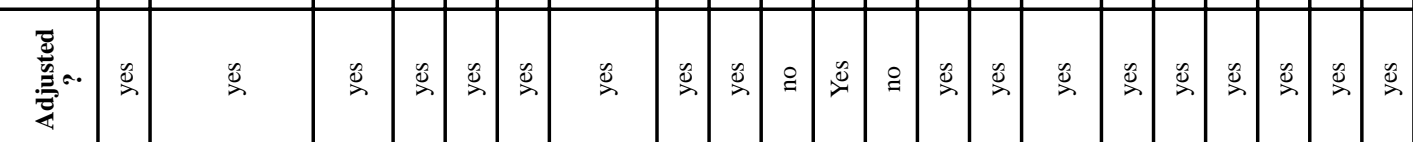

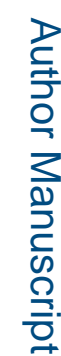

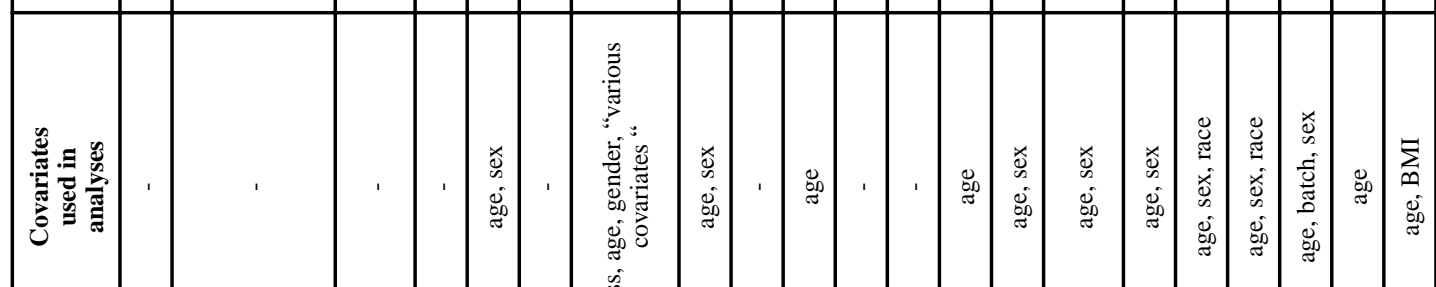

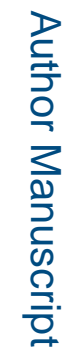

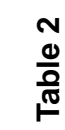

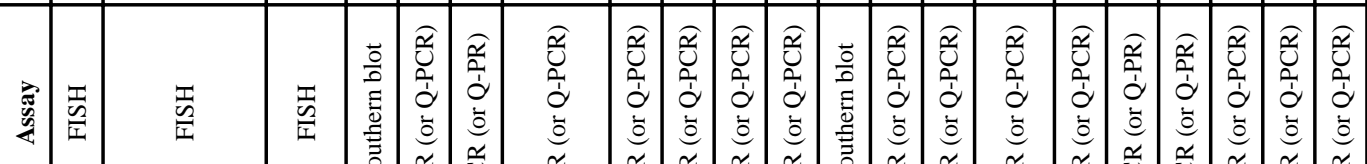

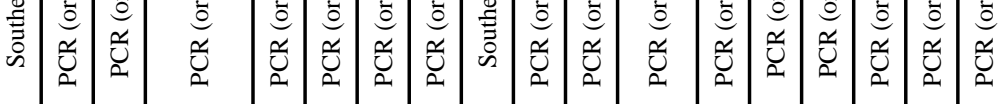

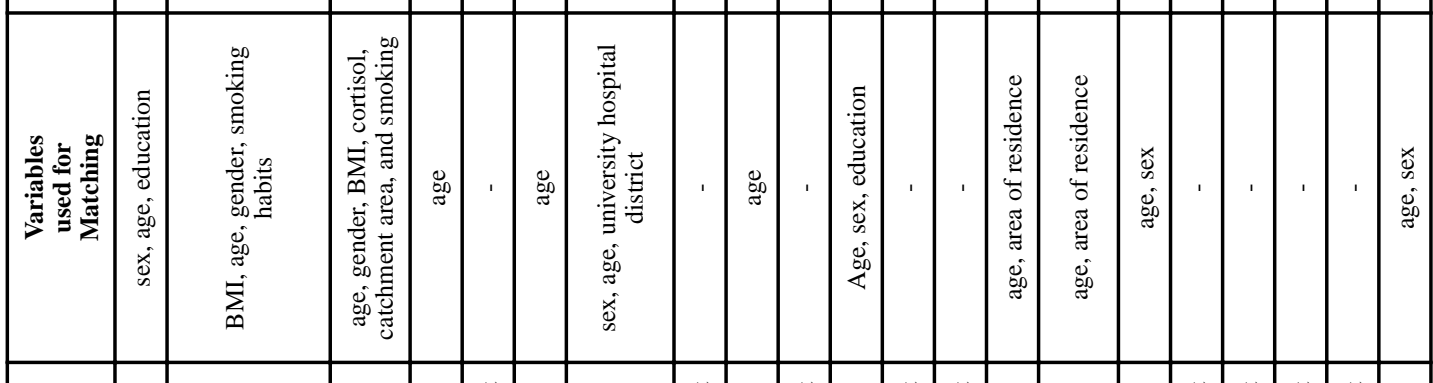

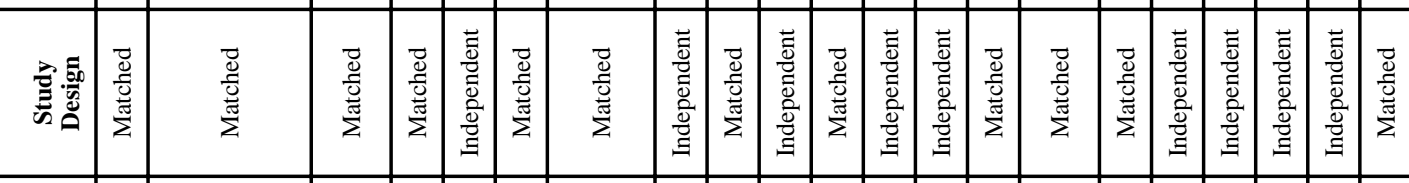

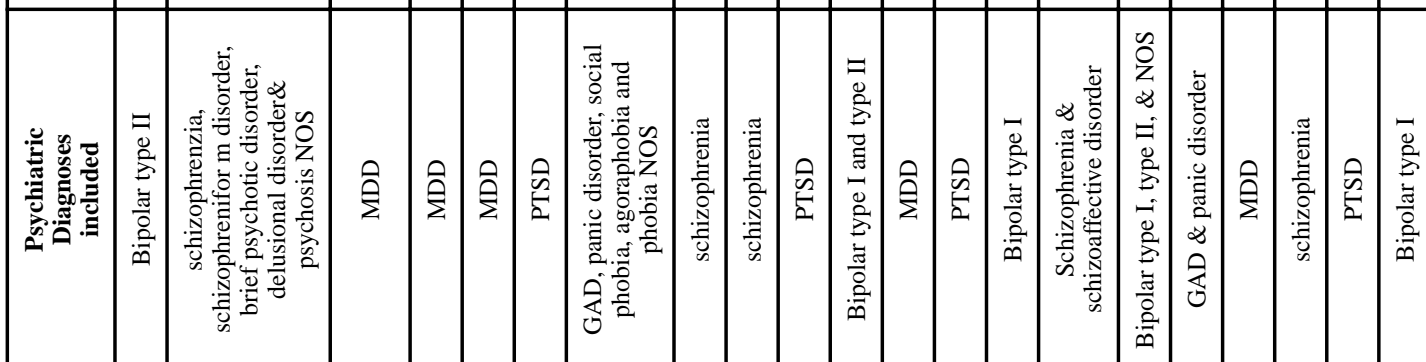

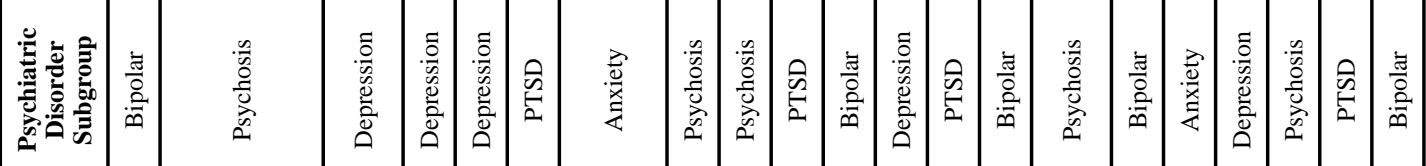

\begin{tabular}{|c|c|c|c|c|c|c|c|c|c|c|c|c|c|c|c|c|c|c|c|}
\hline 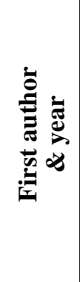 & 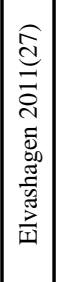 & 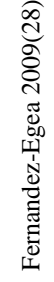 & 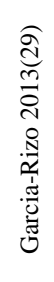 & 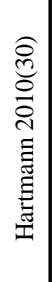 & 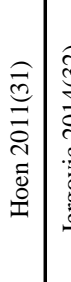 & 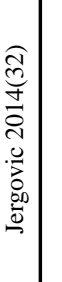 & 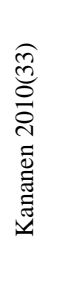 & 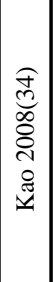 & 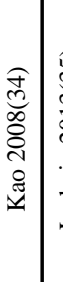 & 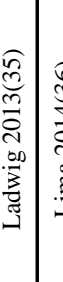 & 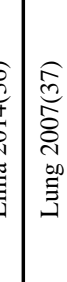 & 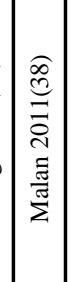 & 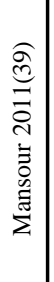 & 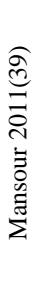 & 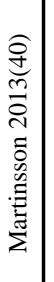 & 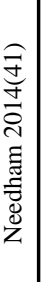 & 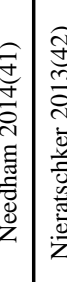 & & 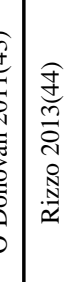 \\
\hline & - & 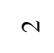 & $m$ & $\nabla$ & $n$ & $\sigma$ & $r$ & $\infty$ & $\sigma$ & $\because=$ & $\Rightarrow \simeq$ & $=$ & \pm & 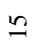 & $\simeq$ & $=$ & $\infty$ & त & \\
\hline
\end{tabular}




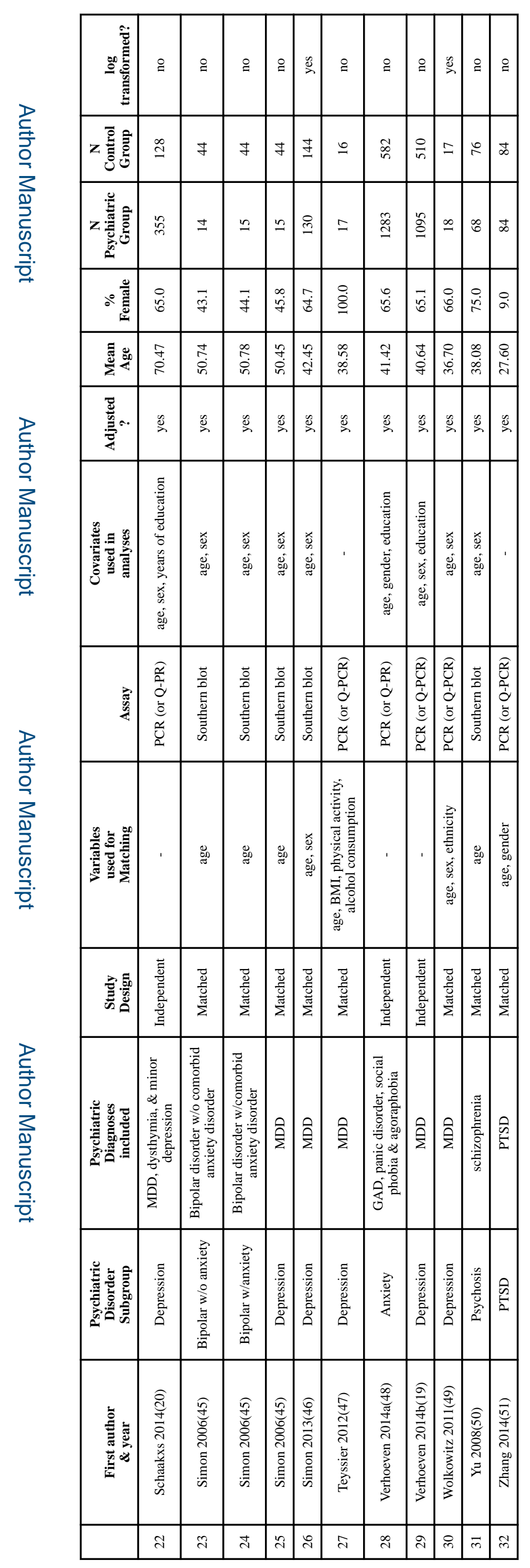




\section{롤 \\ ํㅗㄹ}

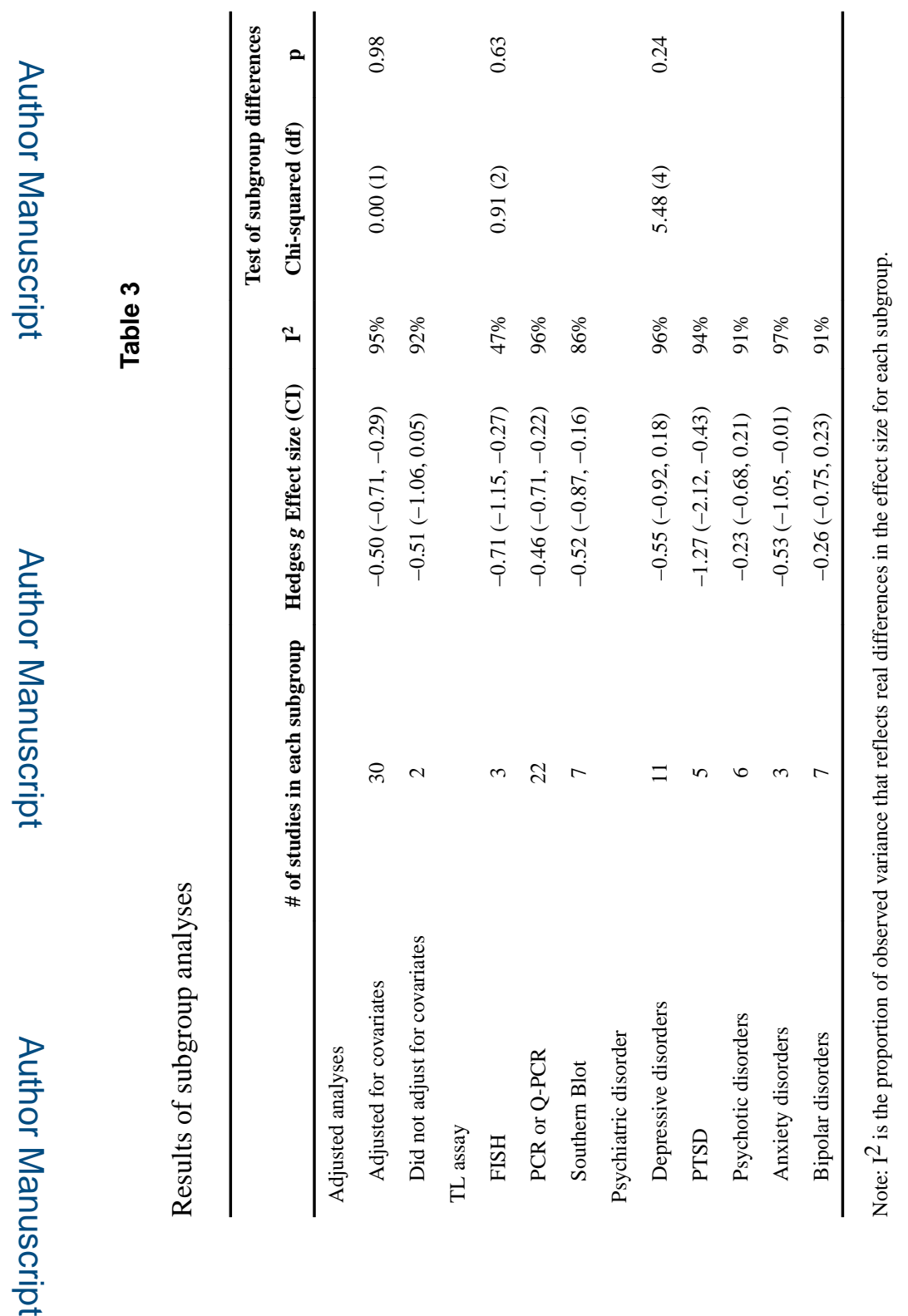

Psychosom Med. Author manuscript; available in PMC 2017 September 01. 


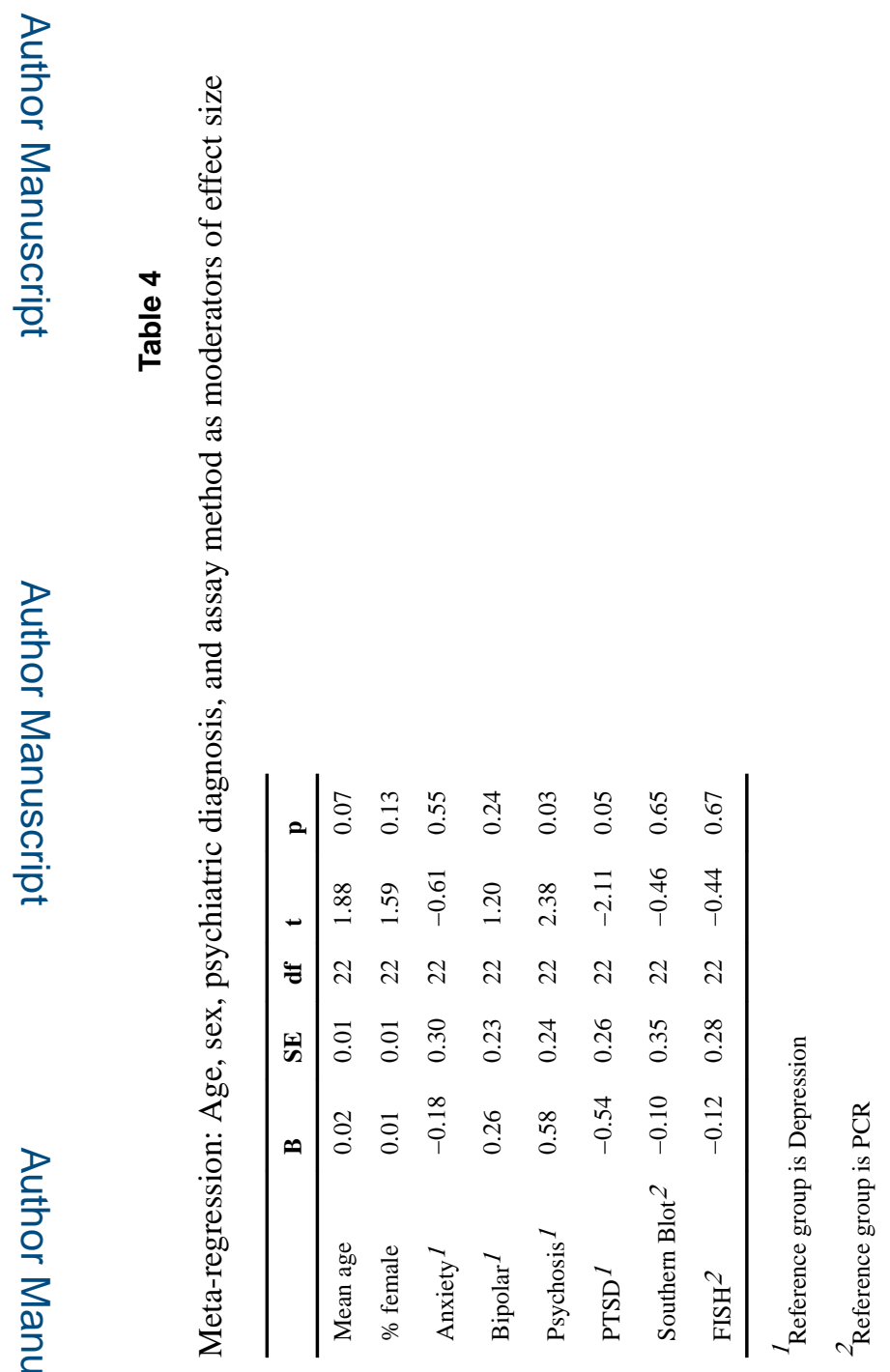

